\section{Tropical Journal of Pathology and Microbiology}

\title{
Unique Features of Hashimoto's Thyroiditis in Coastal South India - a study from a tertiary care hospital
}

\author{
Asokan V. ${ }^{1}$, Rajendran $\mathrm{K}^{2}{ }^{2}$, Sudalaimuthu M. ${ }^{3 *}$ \\ DOI: https://doi.org/10.17511/jopm.2020.i08.02 \\ 1 Vinodhini Asokan, Post-Graduate, Department of Pathology, SRM Medical College Hospital and Research Centre, Faculty of Medicine, SRM \\ Institute of Science and Technology, Chennai, Tamil Nadu, India. \\ 2 Koshalya Rajendran, Senior Resident, Department of Pathology, SRM Medical College Hospital and Research Centre, Faculty of Medicine, \\ SRM Institute of Science and Technology, Chennai, Tamil Nadu, India. \\ 3* Muthu Sudalaimuthu, Associate Professor, Department of Pathology, SRM Medical College Hospital and Research Centre, Faculty of \\ Medicine, SRM Institute of Science and Technology, Chennai, Tamil Nadu, India.
}

Background: Hashimoto's thyroiditis is an autoimmune disorder of thyroid gland. It is one of the common causes of hypothyroidism and is common in females. Generally, Hashimoto's thyroiditis clinically presents as diffuse enlargement of the thyroid and nodular lesions are uncommon. But few recent studies from South India have shown that Hashimoto's frequently presents as nodular enlargement of the thyroid. Such lesions can be easily confused with nodular goitre. Objectives and Aim: Aim of the study is to study the clinicopathological features of Hashimoto's thyroiditis and to estimate the frequency of nodular lesions in Hashimoto's thyroiditis in a tertiary care health centre in coastal South India. Materials and Methods: The present study was done retrospectively on patients diagnosed as Hashimoto's thyroiditis by fine-needle aspiration cytology during the period June 2017 to June 2020. Their clinical details, clinical examination findings including diffuse/nodular nature of the swelling, thyroid hormone status and ultrasound findings were studied. Results: In the present study, 102 cases of Hashimoto's thyroiditis were included, which includes 91 females and 11 males. Patients age ranged from 15 to 63 years with a peak in the fourth decade. Fifty-five cases (53.9\%) were hypothyroid and 43 (42.2\%) were euthyroid. Fifty cases (49\%) presented as nodular lesion out of which 47 cases had multiple nodules. Conclusion: Nodular enlargement of the thyroid is a common finding in Hashimoto's thyroiditis patients. Such cases should not be mistaken for nodular goitre as there is a risk of malignancy in Hashimoto's thyroiditis.

Keywords: Hashimoto's thyroiditis, Hypothyroidism, Cytology, Histopathology

\section{Corresponding Author}

Muthu Sudalaimuthu, Associate Professor, Department of Pathology, SRM Medical College Hospital and Research Centre, Faculty of Medicine, SRM Institute of Science and Technology, Chennai, Tamil Nadu, India.

Email: drmuthus@gmail.com

\section{How to Cite this Article}

Asokan V, Rajendran K, Sudalaimuthu M. Unique Features of Hashimoto's Thyroiditis in Coastal South India - a study from a tertiary care hospital. Trop J Pathol Microbiol. 2020;6(8):466-471.

Available From

https://pathology.medresearch.in/index.php/jopm/ar ticle/view/493
To Browse

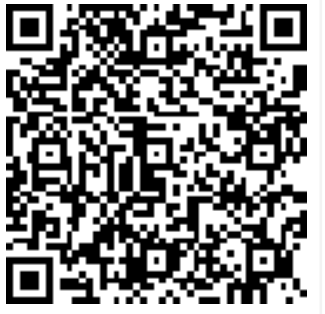

Manuscript Received 2020-11-06

Conflict of Interest No

Review Round 1
$2020-11-26$
Funding
Nil

Review Round 1

$\mathrm{Nil}$
Review Round 2

Ethical Approval Yes
Review Round 3 2020-12-10

Plagiarism X-checker $6 \%$
Accepted 2020-12-24

Note

(C) 2020 by Vinodhini Asokan, Koshalya Rajendran, Muthu Sudalaimuthu and Published by Siddharth Health Research and Social Welfare Society. This is an Open Access article licensed under a Creative Commons Attribution 4.0 International License https://creativecommons.org/licenses/by/4.0/ unported [CC BY 4.0]. 


\section{Introduction}

Hashimoto's thyroiditis (HT) is one of the common causes of hypothyroidism, particularly in the iodine sufficient areas $[1,2]$. This disease is common in females and its incidence is increasing in recent years $[2,3]$. Autoimmune destruction of the thyroid gland by both humoral and cell-mediated immune mechanisms result in the development of this disorder $[1,4,5,6]$.

Fine Needle Aspiration Cytology (FNAC) is a vital investigation which helps to confirm the diagnosis in suspected cases of HT $[5,7]$. Hurthle cells (oncocytic cells) with abundant granular eosinophilic cytoplasm and lymphocytes infiltrating thyroid follicles are common findings in this disorder.[6]

Studies have shown that generally there will be a diffuse enlargement of the thyroid gland in HT [8]. However, few recent studies from south India have shown that nodular enlargement of the thyroid gland is also common in HT $[8,9]$. This assumes clinical significance because there is a risk for thyroid malignancy in patients with HT [2].

Hence such patients with nodular enlargement mustn't be mistaken for nodular goitre. These patients should be correctly diagnosed, adequately treated and followed up. Hence this study was done to identify the frequency of nodular enlargement of the thyroid in patients with $\mathrm{HT}$ in a tertiary care health centre in coastal southern India.

\section{Materials and Methods}

This study was conducted in a tertiary care health centre in south coastal India from March 2019 to June 2020. Cases of HT which have been confirmed either by FNAC or by histopathological examination during the period of June 2017 to June 2020 were included in the present study.

Thus, the present study was a cross-sectional study including both the retrospective cases and the new cases. Cases in which details about nodular/ diffuse nature of the swelling were available were included in the present study and the rest of the cases were excluded from the study.

Patients age, gender, thyroid status, clinical examination findings, thyroid profile and ultrasound findings were retrieved from the medical records department, FNAC notes and specimen gross morphology description notes.
This study was done after obtaining ethical committee approval and following the principals laid down by declaration of Helsinki. FNAC and histopathological slides from these cases were once again examined and the diagnosis was confirmed. Percentage of cases which had diffuse and nodular swelling was calculated.

\section{Results}

A total of 108 patients were identified during the above said period with HT. All these are patients in whom the diagnosis of HT was confirmed with FNAC. Out of these 6 patients were excluded from the study due to incomplete data about the nodular/diffuse nature of the swelling. Thus, a total of 102 patients were included in the study. Among these 25 cases had histopathological confirmation as well.

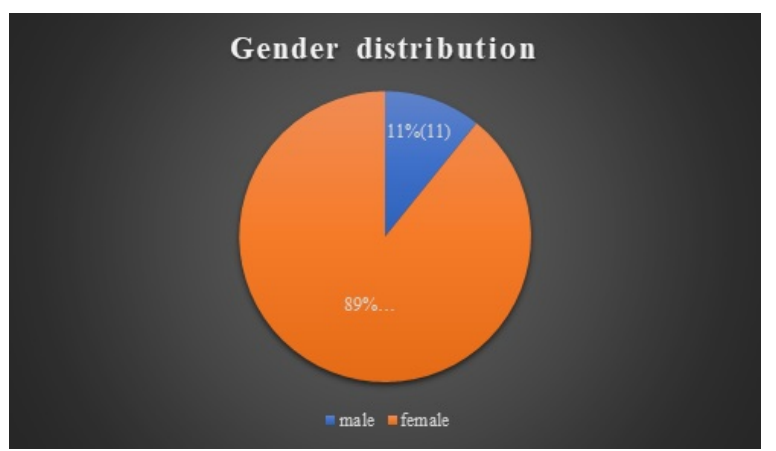

Fig-1: Gender distribution in Hashimoto's thyroiditis.

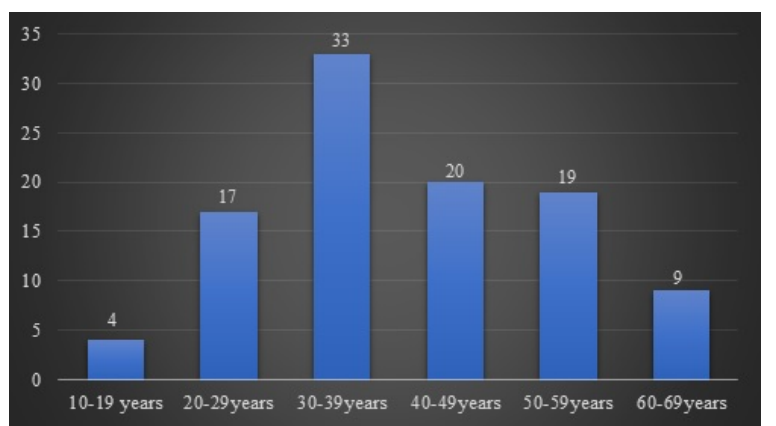

Fig-2: Age distribution in Hashimoto's thyroiditis.

91 of these patients were females and 11 patients were males (Figure 1 ). Thus, the male: female ratio was $1: 8.3$. Age of these patients ranged from 15 years to 63 years with a peak in the fourth decade (Figure 2). Among the 102 cases, 55 cases (53.9\%) were hypothyroid and 43 cases (42.2\%) were euthyroid. 
Among the 102 cases nodular enlargement of the thyroid was noted in 50 cases (49\%). Most of these cases presented with multiple nodules (47 cases). Hypothyroidism was noted in 29 of the 50 cases $(58 \%)$ which showed nodularity and 26 of the 52 cases (50\%) which had diffuse swelling. Ultrasound findings were available in 57 cases. Ultrasound examination findings confirmed the clinical examination findings of the diffuse/nodular nature of the swelling in all the available cases. Among the 25 cases in which the thyroid gland was resected 16 cases $(64 \%)$ had nodules on their cut surface while $9(36 \%)$ cases showed diffuse enlargement of the thyroid without any nodules.

Cytologically (Figure 3 ) these cases showed more lymphocytes in the background with lymphocytes impinging on the follicles. Hurthle cell change and plasma cells in the background were also noted in many cases. Histologically (Figure 4) there was a prominent lymphoid infiltration of the thyroid gland with germinal centre formation. Follicular cells showed hurtle cell change.

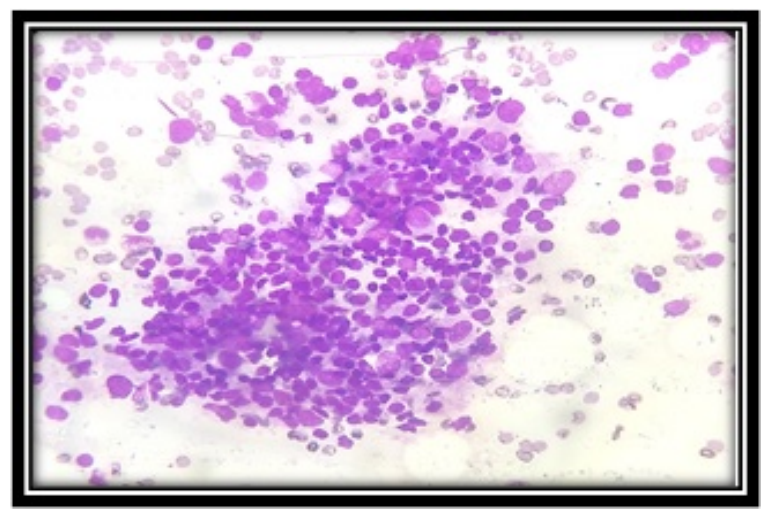

Fig-3: Cytology smear showing lymphocytes infiltrating the follicles along with many lymphocytes in the background, MayGrunwald-Giemsa stain $\times 400$ at half column width.

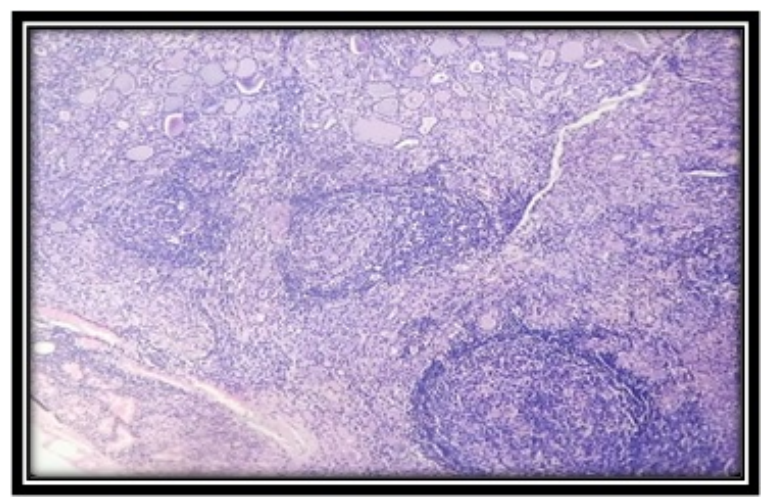

Fig-4: Histopathology image showing many lymphoid follicles with prominent germinal centre along with thyroid follicles, $H$ and $E$ stain $\times 40$ at half column width.

\section{Discussion}

Hashimoto's thyroiditis is the most common autoimmune disease of the thyroid gland with a prevalence rate of $1-4 \%$ [5]. As expected, HT was more common in females in the present study with the male: female ratio of $1: 8.3$ (Figure 1 ). It is well known from previous studies that $\mathrm{HT}$ is more common in females $[10,11]$. However, the male: female ratio differs between studies.

Thomas et al noted the male: female ratio of $1: 8.6$, similar to the present study [11]. However, few other studies have shown a more common incidence in females with male: female ratio up to $1: 31[3,5]$. These variations might be due to the differing incidence in different geographical areas and due to variations in the study inclusion criteria of including only histopathologically resected cases in few studies.

In the present study, $\mathrm{HT}$ was seen more commonly in the age group of 30 to 39 years (Figure 2). Although HT had been mentioned to be more common in 45 to 65 years of age in the Western countries [6], many studies have shown it to be common in India between 20 to 40 years of age [5]. Pabithadevi et al also had noted the peak prevalence between 30 to 40 years of age [5].

Harikrishnan et al also had noted that the prevalence was more common in 20 to 40 years of age [9]. There was no case less than 15 years of age in the present study. Only a few cases were noted less than 20 years after which the incidence started increasing sharply. The incidence decreased again after 60 years of age. These findings were also similar to other studies $[7,9,11]$.

HT is known to be a common cause of hypothyroidism, particularly in areas where iodine deficiency is not common $[2,12]$. In the present study, $53.9 \%$ of the HT patients were hypothyroid. This was similar to the other Indian studies in which the prevalence of hypothyroidism in $\mathrm{HT}$ ranged from $39 \%$ to $72 \%$ [7-9]. At the other end, 3.9\% of cases showed hyperthyroidism. Hyperthyroidism is known to occur in HT during the initial phase which is called Hashitoxicosis. This will be followed later by hypothyroidism. 
Other studies have also reported Hyperthyroidism in up to $25 \%$ of cases of HT $[5,12,18]$. Thus, although less common, it is essential to keep HT also as one of the differential diagnosis in cases with hyperthyroidism. There were no significant differences in the thyroid profile between cases which had a nodular and a diffuse presentation in the present study.

HT is generally known to present with diffuse enlargement of the thyroid gland $[6,8,19]$. However recent studies from the South-eastern Coastal areas of India, where the present study was also conducted, have shown that nodular enlargement of the thyroid is much more common than it was believed earlier $[5,9,10]$. Harikrishnan et al noted in their study that $38.9 \%$ of patients with HT had nodular thyroid enlargement [9]. However, their study had only $18 \mathrm{HT}$ patients.

Pabithadevi et al observed nodular enlargement of the thyroid in $81 \%$ cases of HT. But their study had included only histopathologically confirmed cases [5]. The very high incidence of nodularity among the histopathologically confirmed cases can be partially explained by the fact that cases with nodularity are more likely to be taken up for surgery and the diffuse cases are more likely to be managed conservatively without resection of the thyroid.

Caturegli et al retrospectively studied thyroidectomies done in patients with HT in John Hopkins Hospital over 124 years and noted that thyroidectomy was done in patients with isolated HT predominantly $(60 \%)$ only when there is a nodular goitre or suspicious nodule [2]. Thus, a selection bias is likely when only the histopathologically resected cases are included. Even in the present study, among the cases in which thyroid resection was done, more proportion of cases showed nodularity $(64 \%)$. Thus, the incidence of nodularity in the cytologically confirmed cases will be a better reliable indicator than studying the histopathologically resected cases.

Even among the cytologically confirmed cases, the present study population showed a higher incidence of nodularity when compared to studies from other parts of the country $[7,8]$. In the present study, $49 \%$ of the cytologically confirmed cases showed nodular enlargement of the thyroid. In most of these cases, the enlargement was multinodular. Sahoo et al noted nodular enlargement in only $11.6 \%$ of the HT patients confirmed by cytology [8].
Chandanwale et al in their study from Pune observed nodularity in only $29 \%$ of the HT patients in whom Fine needle aspiration cytology was done [7]. Thus, nodular enlargement of the thyroid in HT seems to be more common in our region.

This difference is clinically significant because the nodular presentation of the swelling in $\mathrm{HT}$ patients can misguide the clinician to a diagnosis of nodular goitre. Confirmation of the diagnosis of HT and adequate follow up is essential because HT is associated with an increased risk of thyroid cancer. Chen et al observed in their study that patients with HT had an 11.8-fold higher risk of thyroid cancer when compared to patients without HT.

Chronic inflammation in HT is believed to play a role in the pathogenesis of these tumours $[13,14]$. The association is more common with papillary carcinoma thyroid [2]. The risk of cancer is more in cases of HT which grossly present with nodularity $[15,16]$. Hence it becomes critical that cases of HT presenting with nodular enlargement are not misinterpreted as nodular goitre.

The present study reiterates the findings of Harikrishnan et al and Pabithadevi et al that nodular enlargement of the thyroid in HT is more common in this part of the country $[5,9]$. Such a difference might not be restricted to our region alone and might be seen in different geographic regions of the world $[16,20]$. Considering that environmental factors do influence $\mathrm{HT}$, as it is more common in iodine sufficient areas, there might be variations in the clinical presentation as well in different geographic regions.

Jayaram et al in their study from Malaysia observed that nodular enlargement was more common in patients with Chinese ethnicity than in patients with Indian ethnicity [16]. Thus, multiple factors seem to play a role and more studies from different geographic regions of the world are needed on this aspect.

The current study had a few limitations. Ultrasound findings were not available in all cases. It was not done probably because of economic constraints. The current study didn't include serum thyroid antibody profile in the present study as it was not available in many cases. Serum antibody results might not be positive in all cytologically confirmed cases as shown in various studies and their diagnostic significance is under scrutiny $[17,18]$. 


\section{Conclusion}

Nodular enlargement of the thyroid gland in HT seems to be more common than thought earlier, at least in our region. Such geographic variations need to be studied in different regions of the world. The present study denotes that all cases with nodular presentation should not be misinterpreted as nodular goitre. They should be correctly diagnosed by necessary investigations and adequately followed up as there is a risk of malignancy in patients with HT.

\section{What does the study add to the existing knowledge?}

It is mentioned widely in the literature that HT often presents as diffuse swelling. But the present study showed that presentation with nodular enlargement was also common in $\mathrm{HT}$, particularly in the current study population. Hence cases with multinodular enlargement of thyroid should not always be interpreted as multinodular goitre and have to be studied further.

\section{Author's contribution}

All the authors, Dr. Vinodhini Asokan, Dr. Koshalya Rajendran, Dr. Muthu Sudalaimuthu contributed equally in the concept, study design, statistical analysis and manuscript preparation.

\section{Reference}

01. Tomer $Y$, Huber A. The etiology of autoimmune thyroid disease, A story of genes and environment. J Autoimmune. 2009;32(3-4)231239.

doi: 10.1016/j.jaut.2009.02.007 [Crossref]

02. Caturegli $P$, De Remigis $A$, Chuang $K$, Dembele M, Iwama A, Iwama S. Hashimoto's thyroiditiscelebrating the centennial through the lens of the Johns Hopkins hospital surgical pathology records. Thyroid. 2013;23(2)142-150. doi: $10.1089 /$ thy.2012.0554 [Crossref]

03. Velayutham K, Selvan S S, Unnikrishnan A G. Prevalence of thyroid dysfunction among young females in a southindian population. India J Endocr Metab. 2015;19(6)781-784. doi: 10.4103/2230-8210.167546 [Crossref]
04. Pyzik A, Grywalska E, Matuszek BM, Rolinski J. Immune disorders in hashomotos thyroiditisWhat do we know so far?. J Immunol Res. 2015. doi: 10.1155/2015/979167 [Crossref]

05. Pabithadevi BM, Shantaraman K. Hashimoto's Thyroiditis-A predominantly Multinodular Thyroid Disorder in Coastal South India. Ann Pathol Lab Med. 2018;5(3)A204-208. doi: 10.21276/APALM.1638 [Crossref]

06. Abbas AK, Aster JC. Robbins and Cotran pathologic basis of disease. 9-ed, New DelhiElsevier. 2015;Ch-24;1082-100.

[Crossref]

07. Chandanwale SS, Nair R, Gambhir A, Kaur S, Pandey A, Shetty A, et al. Cytomorphological spectrum of thyroiditis- A review of 110 cases. J Thyroid Res. 2018.

doi: $10.1155 / 2018 / 5246516$ [Crossref]

08. Sahoo N, Naik S, Mohanty P, Sahoo PN, Das P. The cytomorphological spectrum of Hashimoto thyroiditis and its correlation with serological parameters- A study in the coastal region. J Dr NTR University of Health Sci. 2020;9(1)25.

doi: 10.4103/JDRNTRUHS.JDRNTRUHS_125_19 [Crossref]

09. Harikrishnan V, Alphanso J, Srinivasan C. A case study ina rural tertiary care center. Pacific Group E-J. 2018;5;311-315.

doi: 10.21276/APALM.1755 [Crossref]

10. Zhang JW, Chen ZJ, Gopinathan A. Focal Nodular Hashimoto's Thyroiditis Comparison of Ultrasonographic Features with Malignant and Other Benign Nodules. Ann Acad Med Singap. $2016 ; 45(8) 357-363$.

[Crossref]

11. Bhargav $P$, Shekhar S. Surgical Indications for Goiter with Background Hashimoto's ThyroiditisInstitutional Experience. Indian J Surg. $2011 ; 73(6) 414-418$.

doi: $10.1007 / \mathrm{s} 12262-011-0344-0 \quad$ [Crossref]

12. Thomas $\mathrm{T}$, Sreedharan $\mathrm{S}$, Khadilkar UN, Deviprasad D, Kamath M P, Bhojwani KM, et al. Clinical, biochemical \& cytomorphologic study on Hashimoto's thyroiditis. Indian J Med Res. 2014;140(6)729-735.

[Crossref] 
13. Chen YK, Lin $\mathrm{CL}$, Cheng FT, Sung FC, Kao CH. Cancer risk in patients with Hashimoto's thyroiditis- a nationwide cohort study. Brit ] Cancer. 2013;109(9)2496-2501.

doi: $10.1038 /$ bjc.2013.597 [Crossref]

14. Paparodis $\mathrm{R}$, Imam $\mathrm{S}$, Todorova-Koteva $\mathrm{K}$ et al. Hashimoto's Thyroiditis Pathology and Risk for Thyroid Cancer. Thyroid. 2014;24(7)1107-1114. doi: $10.1089 /$ thy.2013.0588 [Crossref]

15. McManus C, Luo J, Sippel $R$, Chen $H$. Is thyroidectomy in patients with Hashimoto thyroiditis more risky?. J Surg Res. $2012 ; 178(2) 529-532$.

doi: $10.1016 /$ j.jss.2012.09.017 [Crossref]

16. Jayaram G, Iyengar $K R$, Sthaneshwar $P$, Hayati JN. Hashimoto's thyroiditis-A Malaysian perspective. J Cytol. 2007;24(3)119.

doi: 10.4103/0970-9371.41898 [Crossref]

17. Agrawal PC, Naik R, Panda KM. Diagnostic Role of Fine Needle Aspiration Cytology in Thyroiditis along with Thyroid Hormone Assay. Ann App Bio-Sci. 2016;3(1).

Available at [Article] [Crossref]
18. Staii A, Mirocha S, Todorova-Koteva K, Glinberg $\mathrm{S}$, Jaume J. Hashimoto thyroiditis is more frequent than expected when diagnosed by cytology which uncovers a pre-clinical state. Thyroid Res. 2010;3(1)11. doi: $10.1186 / 1756-6614-3-11$ [Crossref]

19. Bhatia A, Rajwanshi A, Dash RJ, Mittal BR. Lymphocytic Thyroiditis-is cytological grading significant? A correlation of grades withclinical, biochemical, ultrasonographic and radionuclide parameters. Cyto J. 2007;4(10). doi:10.1186/1742-6413-4-10 [Crossref]

20. Latina A, Gullo D, Trimarchi $F$ et al. Hashimoto's Thyroiditis: Similar and Dissimilar Characteristics in Neighbouring Areas, Possible Implications for the Epidemiology of Thyroid Cancer. PLOS ONE. 2013;8(3)e55450.

doi: 10.1371/journal.pone.0055450 [Crossref] 